\title{
3D T2 MR Imaging-Based Measurements of the Posterior Cervical Thecal Sac in Flexion and Extension for Cervical Puncture
}

\author{
(D) M.P. Bazylewicz, DiD. Berkowitz, and (D)A. Sayah
}

\begin{abstract}
BACKGROUND AND PURPOSE: The current standard technique for cervical puncture involves prone positioning with neck extension. The purpose of this study was to compare measurements of the posterior cervical thecal sac during neck flexion and extension in supine and prone positions by using high-resolution MR imaging to help determine the optimal positioning for cervical puncture.
\end{abstract}

MATERIALS AND METHODS: High-resolution T2-weighted MR imaging was performed of the cervical spine in 10 adult volunteers 18 years of age and older. Exclusion criteria included the following: a history of cervical spine injury/surgery, neck pain, and degenerative spondylosis. Images of sagittal 3D sampling perfection with application-optimized contrasts by using different flip angle evolutions were obtained in the following neck positions: supine extension, supine flexion, prone extension, and prone flexion. The degree of neck flexion and extension and the distance from the posterior margin of the spinal cord to the posterior aspect of the $\mathrm{Cl}-\mathrm{C} 2$ thecal sac were measured in each position.

RESULTS: The mean anteroposterior size of the posterior $\mathrm{C} 1-\mathrm{C} 2$ thecal sac was as follows: $4.76 \mathrm{~mm}$ for supine extension, $3.63 \mathrm{~mm}$ for supine flexion, $5.00 \mathrm{~mm}$ for prone extension, and $4.00 \mathrm{~mm}$ for prone flexion. Neck extension yielded a larger CSF space than flexion, independent of supine/prone positioning. There was no correlation with neck angle and thecal sac size.

CONCLUSIONS: The posterior $\mathrm{Cl}-\mathrm{C} 2$ thecal sac is larger with neck extension than flexion, independent of prone or supine positioning. Given that this space is the target for cervical puncture, findings suggest that extension is the ideal position for performing the procedure, and the decision for prone-versus-supine positioning can be made on the basis of operator comfort and patient preference/ability.

ABBREVIATION: SPACE = sampling perfection with application-optimized contrasts by using different flip angle evolution

O ften the approach for accessing the thecal sac for CSF sampling or myelography is via lumbar puncture. There are subsets of patients, however, in whom lumbar puncture is not possible or is contraindicated. These include patients with severe lumbar spondylosis, extensive bony lumbar fusion, lumbar canal stenosis, spinal dysraphism, extensive lumbar hardware, and lumbar epidural abscess. In these cases, cervical puncture may be performed as an alternative. For cervical myelography, cervical puncture may actually be the preferred method for instillation of intrathecal contrast.

Received July 14, 2015; accepted after revision August 14.

From the Division of Neuroradiology, Department of Radiology, Medstar Georgetown University Hospital, Washington, DC.

Paper previously presented at: American Society of Neuroradiology Annual Meeting and the Foundation of the ASNR Symposium, May 17-22, 2014; Montreal, Quebec, Canada.

Please address correspondence to Anousheh Sayah, MD, Department of Radiology, Medstar Georgetown University Hospital, 3800 Reservoir Rd, NW, CG201, Washington, DC 20007; e-mail: anousheh.sayah@gunet.georgetown.edu

http://dx.doi.org/10.3174/ajnr.A4564
Although its use is being curbed by heavily T2-weighted, highresolution MR imaging techniques, cervical myelography is still indicated in patients who have a contraindication to MR imaging or equivocal findings on MR imaging or who have failed MR imaging. Administering contrast via cervical puncture has several advantages, including less dilution of contrast within the cervical canal, better control of contrast to prevent intracranial spillage, and the ability to perform the procedure with the patient in a prone or supine position. Additionally, cervical puncture can be helpful to delineate the upper margin of an obstructive mass within the spinal canal below the cervical level. Disadvantages include a slightly increased risk of damage to nearby structures such as the spinal cord, vessels, or nerves. ${ }^{1,2}$

C1-C2 puncture for myelography is often performed with the patient in the prone position with the neck extended, though the procedure can be performed with patients in the lateral decubitus and supine positions. ${ }^{3,4}$ Neck extension is helpful in the prevention of intrathecal contrast spilling into the intracranial space. This positioning may also be used for $\mathrm{C} 1-\mathrm{C} 2$ puncture for CSF 
sampling, though there is no contrast as in myelography to warrant the extended neck position. Under fluoroscopic guidance, the needle is advanced into the posterior thecal sac between the $\mathrm{C} 1$ and C2 vertebrae at approximately the junction of the anterior two-thirds and posterior one-third of the spinal canal. ${ }^{3}$ As a result, the size of the posterior thecal sac in various neck positions during puncture is of interest. That the diameter of the spinal canal varies on imaging with neck position, notably in flexion or extension, is well-documented; however, these studies are focused on the mid- and lower cervical spine in regard to stenosis from spondylotic change. ${ }^{5-7}$ Measurements of the posterior cervical thecal sac are reported with $\mathrm{x}$-ray myelography, with mention of a subjective change in dural configuration and lack of subjective movement of the cord at the $\mathrm{C} 1-\mathrm{C} 2$ level on flexion and extension. ${ }^{8}$ Recently, thin-section MR imaging techniques have been used to assess cervical spinal canal dimensions in healthy volunteers. ${ }^{9}$

To our knowledge, no study has confirmed that there is more space in the posterior thecal sac at $\mathrm{C} 1-\mathrm{C} 2$ with neck extension over flexion or with prone-versus-supine positioning. The purpose of this study was to compare measurements of the posterior cervical thecal sac at $\mathrm{C} 1-\mathrm{C} 2$ during neck flexion and extension in the supine and prone positions by using high-resolution MR imaging in healthy volunteers, to determine which position allows the largest CSF space for cervical puncture.

\section{MATERIALS AND METHODS \\ Patients}

The Georgetown University Hospital institutional review board approved this prospective, Health Insurance Portability and Accountability-compliant study. The study included 10 healthy volunteers. The inclusion criterion was age older than 18 years. Exclusion criteria were the following: history of cervical spine injury, known cervical disc herniations, cervical canal or neuroforaminal stenosis, or cervical spine surgery; acute or chronic neck pain; and any contraindication to MR imaging. The mean age of the subjects was 30.3 years (range, 26-34 years). There were 6 male and 4 female subjects. Informed consent was obtained from all subjects for a noncontrast MR imaging of the cervical spine.

\section{MR Imaging Evaluation}

Each subject underwent 3T MR imaging (Magnetom Verio; Siemens, Erlangen, Germany) of the cervical spine by using a 6element body surface coil and a 16-element table spine coil. Sequences were obtained in the following 4 neck positions: prone flexion, prone extension, supine flexion, and supine extension. In each position, a single high-resolution sagittal T2 sampling perfection with application-optimized contrasts by using different flip angle evolution (SPACE; Siemens) sequence was performed through the cervical spine by using isotropic voxels. The SPACE sequence involved the following imaging parameters: TE, $123 \mathrm{~ms}$; TR, $1200 \mathrm{~ms}$; flip angle, $125^{\circ}$; partition thickness, $0.9 \mathrm{~mm}$; FOV, $280 \times 280 \mathrm{~mm}$; matrix size, $320 \times 317$; receiver bandwidth, 744 $\mathrm{Hz}$; parallel imaging factor, 2; 2 excitations. Each sequence was performed with the patient in the maximum amount of neck flexion or extension that could be maintained for the entire scan to
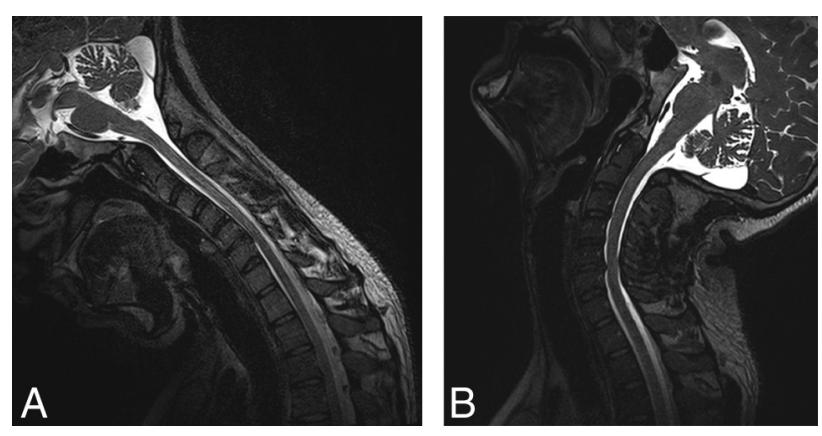

FIG 1. Sagittal T2 SPACE in the following neck positions: supine flexion $(A)$ and prone extension $(B)$.

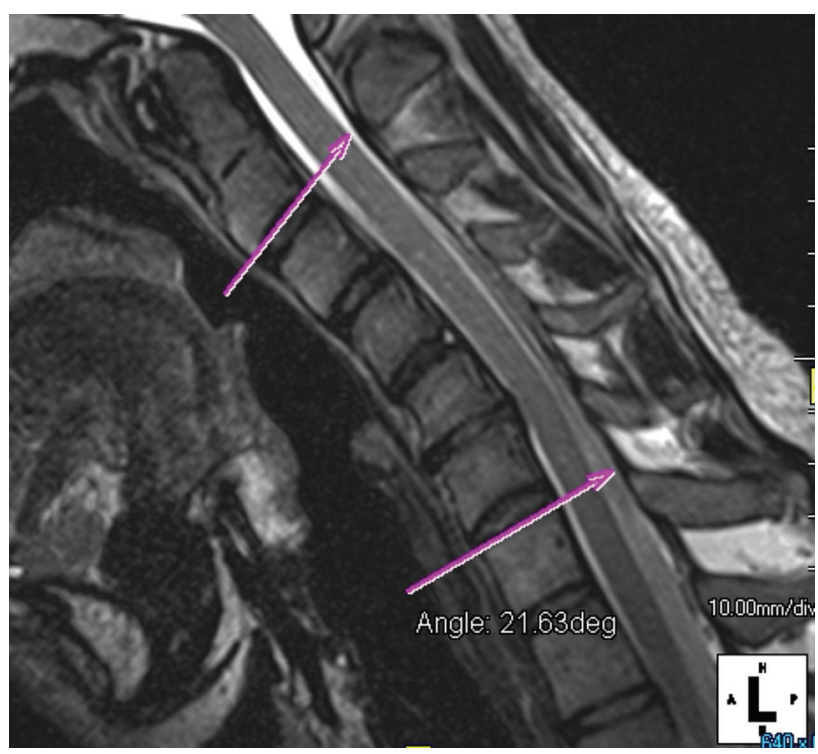

FIG 2. Sagittal T2 SPACE in the prone flexion position with angle measurements obtained from the lines drawn parallel to the inferior endplate of $\mathrm{C} 2$ and superior endplate of $\mathrm{C} 7$.

prevent motion (Fig 1). Scanning time was 5 minutes 18 seconds for each position.

\section{Image Analysis}

All measurements were made on a true midline sagittal image of the cervical spine. The midline image was determined via $3 \mathrm{D}$ manipulation of the isotropic data on a separate workstation (AquariusNET; TeraRecon, San Mateo, California). The angle of cervical spine flexion and extension, defined as the angle between a line drawn parallel to the inferior endplate of $\mathrm{C} 2$ and a second line drawn parallel to the superior endplate of $\mathrm{C} 7$, was measured in each patient (Fig 2). The posterior thecal sac anteroposterior distance was measured in each subject with each neck position. These measurements were obtained by drawing a line from the dorsal spinal cord to the posterior wall of the spinal canal midway between the $\mathrm{C} 1$ and $\mathrm{C} 2$ spinous processes (Fig 3).

\section{Statistical Analysis}

Measurements within patients were not considered independent. Therefore, we used a repeated measures ANOVA, assuming a covariance structure of compound symmetry among the 4 different positions. Each position was treated as a fixed effect and com- 

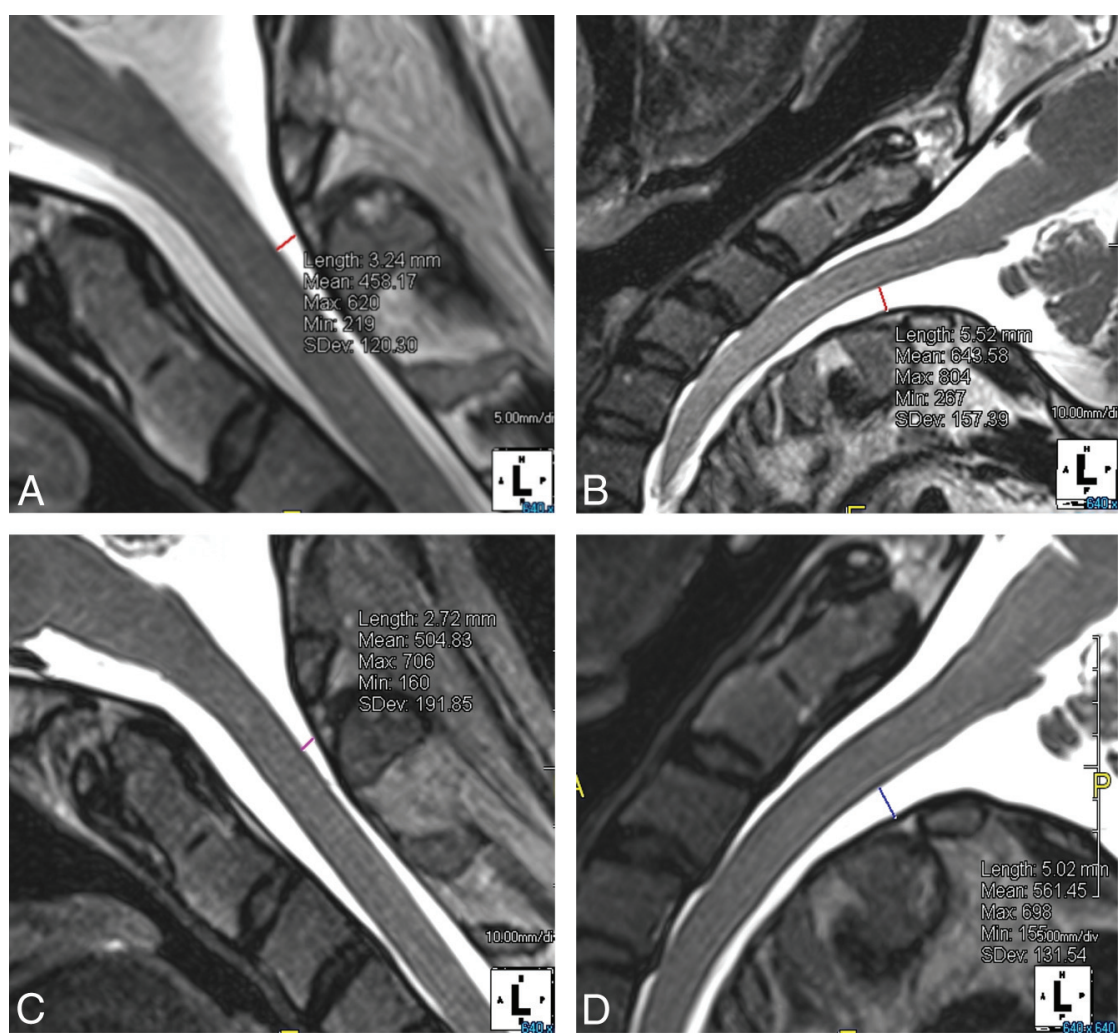

FIG 3. Anteroposterior measurements of the posterior $\mathrm{Cl}-\mathrm{C} 2$ thecal sac obtained off reformatted true midline images of the sagittal T2 SPACE in the same patient in prone flexion $(A)$, prone extension $(B)$, supine flexion $(C)$, and supine extension $(D)$.

Statistical analysis of $\mathrm{C} 1-\mathrm{C} 2$ posterior thecal sac measurements in various neck positions

\begin{tabular}{lllllll}
\hline & \multicolumn{6}{c}{ Analysis Variable: Distance $(\mathrm{mm})$} \\
\cline { 2 - 8 } \multicolumn{1}{c}{ Position } & No. & Mean & Median & SD & Minimum & Maximum \\
\hline Prone extension & 10 & 5.00 & 4.69 & 1.29 & 3.19 & 7.16 \\
Prone flexion & 10 & 4.00 & 3.72 & 1.12 & 2.42 & 6.21 \\
Supine extension & 10 & 4.76 & 4.85 & 1.23 & 3.03 & 7.03 \\
Supine flexion & 10 & 3.62 & 3.18 & 1.25 & 1.56 & 5.56 \\
\hline
\end{tabular}

pared with each of the other 3 positions. Correlative analysis of neck angle values and thecal sac size was also performed. A $P$ value $<.01$ was considered statistically significant. Analysis was performed by using SAS 9.3 software (SAS Institute, Cary, North Carolina).

\section{RESULTS}

The mean angle of extension was $37.3^{\circ}$ for the supine and $39.8^{\circ}$ for the prone position. The mean angle of flexion was $28.6^{\circ}$ for the supine and $28.8^{\circ}$ for the prone position. The mean anteroposterior dimensions of the posterior thecal sac at the $\mathrm{C} 1-\mathrm{C} 2$ level were as follows: $4.00 \pm 1.12 \mathrm{~mm}$ for prone flexion, $5.00 \pm 1.29 \mathrm{~mm}$ for prone extension, $3.62 \pm 1.25 \mathrm{~mm}$ for supine flexion, and $4.76 \pm$ $1.23 \mathrm{~mm}$ for supine extension (Table). There was a statistically significant difference in distances measured at different positions at $P<.01$.

The posterior thecal sac size for each position was held as a fixed variable and then compared with the measurements in each of the other 3 positions. Comparing with prone flexion, we calculated the following $P$ values: prone extension at $P=.0003$, supine extension at $P=.004$, and supine flexion at $P=.128$. Comparing with prone extension, we calculated the following $P$ values: supine flexion at $P=.0001$ and supine extension at $P=.342$. Compared with supine flexion, supine extension demonstrated $P=.0001$. In summary, statistically significant differences $(P<.01)$ were found between prone flexion and prone extension, prone flexion and supine extension, prone extension and supine flexion, and supine flexion and supine extension. Three of these significant correlations met even highly rigorous significance criteria at $P<.0001$ (prone flexion versus prone extension; prone extension versus supine flexion; and supine flexion versus supine extension).

Additional correlative analysis between the distance and neck angle at each position resulted in the following $P$ values: prone flexion at .963 , prone extension at .983 , supine flexion at .290 , and supine extension at .257. There was no significant association between distance and neck angle at any position.

Overall results demonstrate that the posterior thecal sac is larger with the extension position compared with flexion but that there is no significant difference in the posterior thecal sac size between prone and supine imaging.

\section{DISCUSSION}

Cervical puncture is a very effective approach for CSF sampling and instillation of intrathecal contrast for myelography. Although lumbar puncture is often used for these purposes, myriad indications would warrant $\mathrm{C} 1-\mathrm{C} 2$ puncture into the thecal sac. These mostly include limited or contraindicated access at the level of the lumbar spine due to extensive bony fusion, epidural abscess, spondylosis, and so forth. Additionally one may prefer to inject intrathecal contrast into the cervical thecal sac for cervical myelography due to the advantages, such as less contrast dilution and better control of contrast to prevent intracranial spill.

The use of cervical puncture seems to be waning possibly due to growing inexperience with the technique and concern for the associated risks, mainly involving cervical cord injury. However, in 2009, Yousem et $\mathrm{al}^{1}$ provided a discussion about the relevance of cervical puncture with regard to the current standard of practice and found that there are still reasonable indications for cervical puncture and that the complication rate is low when performed by experienced neuroradiologists. Additionally, a 2008 study of cervical myelography at 1 large center revealed that the authors' major approach was cervical puncture at a ratio of $6: 1$, with a slightly higher prevalence of documented minor adverse reactions over lumbar puncture. ${ }^{10}$

Complications of cervical puncture include the potential for

AJNR Am J Neuroradiol 37:579-83 Mar 2016 www.ajnr.org

581 
spinal cord puncture and injection of contrast into the cord parenchyma. ${ }^{1-13}$ Another concern, albeit less common, is injury to nearby cervical nerves and major arteries such as the vertebral or posterior inferior cerebellar arteries, resulting in symptoms related to cord, brain stem, and brain infarcts. There are also case reports of spinal hematoma leading to a variety of complications, including cord compression and death. ${ }^{14-16}$

Cervical puncture can be performed with the neck flexed or extended and in either the prone or supine position. Standard positioning of the patient for cervical puncture involves placing the patient's neck in a prone extended position. In this study, we evaluated the anteroposterior size of the posterior cervical thecal sac in various neck positions to determine which yields the largest CSF space for access, theoretically decreasing the risk of cord injury. To our knowledge, there are no prior studies that measure the size of the posterior upper cervical thecal sac in these various positions. Orrison et $\mathrm{al}^{8}$ performed a postmortem study and found that the average posterior thecal sac size at $\mathrm{C} 1-\mathrm{C} 2$ in the neutral position was $4.3 \mathrm{~mm}$, in a range similar to that of measurements obtained in our study. Most interesting, Orrison et al also showed up to $1 \mathrm{~cm}$ of tenting of the dura ahead of the needle in cervical puncture before CSF was seen in the hub.

We used high-resolution 3D T2 SPACE MR imaging to reformat the data and determine the most accurate midline position of the spinal canal. This sequence has been reported by others to be of high quality and clinically acceptable for imaging of the spine and spinal canal. ${ }^{17,18}$ Our measurement and analysis of healthy volunteers by using MR imaging of the cervical spine demonstrates that the posterior cervical subarachnoid space is approximately 25\% larger with neck extension than with neck flexion. This result is independent of prone or supine positioning.

Prior studies have shown that the upper cervical levels from C2 to $\mathrm{C} 4$ (starting at the inferior edge of $\mathrm{C} 2$ ) demonstrate increases in the ventral subarachnoid space and decreases in the dorsal subarachnoid space on neck extension. Our measurements were obtained at the mid-C2 level (above the levels discussed in prior reports); in all subjects in both the prone and supine positions, the reverse was observed with decreases in the ventral subarachnoid space and increases in the dorsal space. On the basis of our evaluation of the images obtained in all of our subjects in the various positions, we postulate that the dynamics above the inferior margin of $\mathrm{C} 2$ vary from that observed in the remainder of the cervical spine. We theorize that the cervicomedullary cord remains in a relatively stable position between the flexed and extended positions in comparison with the bony spine and it is the upper cervical vertebral bodies that move closer to the anterior cord in extension, in effect widening the posterior thecal sac.

Although the study was limited by the small number of subjects, most of the differences between extension and flexion were highly statistically significant, meeting even the stringent criteria of $P<.0001$. A larger number of subjects would be required to see if the lack of a significant difference between the prone and supine position was due to a true lack of difference or the limited power of the study. Another possible limitation included small inconsistencies in placing calipers during measurements, given the relatively small size of the posterior thecal sac and mild motion artifacts. Additionally, we did not consider sex or height analyses, mainly due to the number of subjects in the study, and this analysis may be a topic of interest in future studies.

Some may argue that the homogeneous, young, healthy nature of our subject group does not reflect that seen on a clinical basis. The strongest indications for cervical puncture in our institution are for CSF sampling and myelography in patients in whom lumbar puncture is not possible for reasons such as extensive lumbar bony fusion or lumbar epidural abscess. These indications occur in patients young and old, with or without cervical spondylosis. As such, our study population included healthy young volunteers to determine the effect of flexion and extension without other confounding factors.

We think that the increase in posterior thecal sac size in the extended neck position theoretically decreases the risk of the needle coming in contact with the spinal cord during cervical puncture. However, prolonged neck extension may be difficult in a subset of patients who have significant cervical disease. In cases in which prone positioning of the patient may not be possible due to anatomic limitations, medical conditions, and safety concerns, it is important to know that supine positioning does not have a significant impact on the space available for needle placement. This is of great importance in patients with cervical disease who may have problems with prone-versus-supine positioning.

Future studies could be performed including more subjects to increase the power of the analysis and possibly including patients who have clinical indications for cervical puncture to see if this patient population has results similar to those in healthy subjects.

\section{CONCLUSIONS}

The posterior cervical thecal sac at C1-C2 is larger in extension than flexion, suggesting that extension is the ideal position for cervical puncture for CSF sampling or cervical myelography. There is no difference in posterior cervical thecal sac size in proneversus-supine positioning.

\section{REFERENCES}

1. Yousem DM, Gujar SK. Are C1-2 punctures for routine cervical myelography below the standard of care? AJNR Am J Neuroradiol 2009;30:1360-63 CrossRef Medline

2. Robertson HJ, Smith RD. Cervical myelography: survey of modes of practice and major complications. Radiology 1990;174:79-83 CrossRef Medline

3. Orrison WW, Eldevik OP, Sackett JF. Lateral C1-2 puncture for cervical myelography, part III: historical, anatomic, and technical considerations. Radiology 1983;146:401-08 CrossRef Medline

4. ACR-ASNR-SPR practice parameter for the performance of myelography and cisternography. Updated 2014. http://www.acr.org/ / media/ACR/Documents/PGTS/guidelines/Myelography.pdf. Accessed October 9, 2015

5. Muhle C, Wiskirchen J, Weinert D, et al. Biomechanical aspects of the subarachnoid space and cervical cord in healthy individuals examined with kinematic magnetic resonance imaging. Spine (Phila Pa 1976) 1998;23:556-67 CrossRef Medline

6. Muhle C, Metzner J, Weinert D, et al. Classification system based on kinematic MR imaging in cervical spondylitic myelopathy. AJNR Am J Neuroradiol 1998;19:1763-71 Medline

7. Bartlett RJ, Hill CA, Rigby AS, et al. MRI of the cervical spine with neck extension:is it useful? Br J Radiol 2012;85:1044-51 CrossRef Medline

8. Orrison WW, Sackett JF, Amundsen P. Lateral C1-2 puncture for 
cervical myelography, part II: recognition of improper injection of contrast material. Radiology 1983;146:395-400 CrossRef Medline

9. Ulbrich EJ, Schraner C, Boesch C, et al. Normative MR cervical spinal canal dimensions. Radiology 2014;271:172-82 CrossRef Medline

10. Chin KR, Eiszner JR, Huang JL, et al. Myelographic evaluation of cervical spondylosis: patient tolerance and complications. J Spinal Disord Tech 2008;21:334-37 CrossRef Medline

11. Johansen JG, Orrison WW, Amundsen P. Lateral ral C1-2 puncture for cervical myelography, part I: report of a complication. Radiology 1983;146:391-93 CrossRef Medline

12. Nakstad PH, Kjartansson O. Accidental spinal cord injection of contrast material during cervical myelography with lateral C1-C2 puncture. AJNR Am J Neuroradiol 1988;9:410 Medline

13. Servo A, Laasonen EM. Accidental introduction of contrast medium into the cervical spinal cord: a case report. Neuroradiology 1985;27: 80-82 CrossRef Medline
14. Rogers LA. Acute subdural hematoma and death following lateral cervical spinal puncture: case report. J Neurosurg 1983;58:284-86 CrossRef Medline

15. Abla AA, Rothfus WE, Maroon JC, et al. Delayed spinal subarachnoid hematoma: a rare complication of $\mathrm{C} 1-\mathrm{C} 2$ cervical myelography. AJNR Am J Neuroradiol 1986;7:526-28 Medline

16. Mapstone TB, Rekate HL, Shurin SB. Quadriplegia secondary to hematoma after lateral C-1, C-2 puncture in a leukemic child. Neurosurgery 1983;12:230-31 CrossRef Medline

17. Lighvani AA, Melhem ER. Advances in high-field MR imaging of the spine. Appl Radiol 2009;38:18-27

18. Meindl T, Wirth S, Weckbach S, et al. Magnetic resonance imaging of the cervical spine: comparison of $2 \mathrm{D} \mathrm{T} 2$-weighted turbo spin echo, 2D T2 ${ }^{\star}$ weighted gradient-recalled echo and 3D T2-weighted variable flip-angle turbo spin echo sequences. Eur Radiol 2009;19: 713-21 CrossRef Medline 